\section{SAT0426 HIGH LEVELS OF EMPLOYMENT BUT PERSISTING WORK PLACE IMPAIRMENT IN PATIENTS WITH AXIAL SPONDYLOARTHRITIS ON BIOLOGIC THERAPY}

T.G. Nadin ${ }^{1}$, D. Wallis ${ }^{1}$, C. Holroyd ${ }^{1}$, P. Clayton ${ }^{1}$, R. Armstrong ${ }^{1}$, C. Cooper ${ }^{2}$, B. Davidson ${ }^{1}$, N. Harvey ${ }^{2}$, E. Dennison ${ }^{2}$, R. Seth ${ }^{1}$, K.E. Walker-Bone ${ }^{2}$, S. Bennett ${ }^{1}$, C.J. Edwards $1,3 .{ }^{1}$ Rheumatology; ${ }^{2}$ MRC Lifecourse Epidemiology Unit; ${ }^{3}$ NIHR Wellcome Trust Clinical Research Facility, University Hospital Southampton, NHS Foundation Trust., Southampton, United Kingdom

Background: Axial spondyloarthritis (axSpA) is associated with reduced work productivity. Biologic therapies have demonstrated a positive impact on workrelated outcomes in clinical trials but real world data are limited.

Objectives: To investigate the prevalence and predictors of work impairment and disability in patients with axSpA attending a biologic therapy clinic.

Methods: Data were collected from a single-centre, prospective cohort of patients with axSpA treated with biologic therapy. Standardised outcome measures, including the Work Productivity and Activity Impairment (WPAI) Questionnaire for axSpA, are collected every 6 months. Data from the most recent clinic visit were analysed using IBM SPSS Statistics 24. Disease activity was compared between employed patients and those unemployed due to disability from axSpA. The effect of smoking status and gender on work related outcomes was analysed. The relationship between work-related outcomes and disease severity was investigated using Pearson's correlation. Significance was defined as $p<0.05$ with Bonferroni correction.

Results: Data were available for 165 patients (mean age 47.6 years, $75 \%$ male, $21 \%$ current smokers). Mean time since diagnosis was 15.4 years and mean duration of biologic therapy 4.7 years, with $19 / 165(12 \%)$ on a reduced dose regimen. Mean BASDAI was 4.0, ASQoL 6.6, BAS-G 3.9 and spinal pain VAS 4.0. Employment data were provided by 144 patients of whom $99 / 144(69 \%)$ were employed; $17 / 144(12 \%)$ not working due to disability caused by SpA; $19 / 144$ $(13 \%)$ retired; 5/144 (4\%) unemployed; 2/144 (1\%) full-time education; and 2/144 (1\%) full-time parents. Of the 144 patients in employment, $8(6 \%)$ had missed hours of work in the week prior to the last clinic visit due to axial $\mathrm{SpA}$ (mean hours missed $=13$ ). There was no difference between males and females in (i) the proportion of patients employed or (ii) the proportion not working due to disability from SpA.

Mean impairment while working due to axial SpA was $23 \%$ and impairment of regular daily activities $35 \%$. There was no significant difference in percentage work impairment between males and females. BASDAI was higher in patients unemployed due to $\operatorname{SpA}(7.1 \pm 1.6)$ compared to those who were employed $(3.5 \pm 2.2, p<0.001)$. Higher levels of work impairment were observed in current smokers compared to previous smokers and never smokers $(p=0.003)$. Positive correlations were found between individual WPAI domains and each of BASDAI, BAS-G, ASQoL and spinal pain VAS $(p<0.001)$

Conclusions: In this cohort of axial SpA patients on biologic therapy, the majority were employed and few reported missing time at work. As expected, disease activity was higher in patients unemployed due to disability compared to those who were currently in paid work. Gender did not appear to affect employment rates, disability rates or work impairment. Smoking was associated with increased work impairment. The impact of disease on employment should be considered in the clinic and strategies for enhancing work participation directed towards those patients most at risk.

Disclosure of Interest: T. Nadin: None declared, D. Wallis Grant/research support from: Janssen, MSD and Pfizer, C. Holroyd Paid instructor for: BMS, Abbvie, Chugai and Janssen., P. Clayton: None declared, R. Armstrong: None declared, C. Cooper: None declared, B. Davidson: None declared, N. Harvey: None declared, E. Dennison: None declared, R. Seth: None declared, K. Walker-Bone: None declared, S. Bennett: None declared, C. Edwards Consultant for: Abbvie, Pfizer, Lilly, Celltrion, Mundipharma, Samsung, Anthera, UCB, Celgene, Roche, BMS, Jansen, Novartis and UCB., Speakers bureau: Abbvie, Pfizer, Lilly, Celltrion, Mundipharma, Samsung, Anthera, UCB, Celgene, Roche, BMS, Jansen, Novartis and UCB.

DOI: 10.1136/annrheumdis-2017-eular.2075

\section{SAT0427 ASAS HEALTH INDEX: VALIDITY AND RELIABILITY IN} ARGENTINEAN PATIENTS WITH SPONDYLOARTHRITIS

V.M. Duarte ${ }^{1}$, U. Kiltz ${ }^{2}$, V. Navarro-Compán ${ }^{3}$, N. Lloves ${ }^{1}$, G. Crespo Amaya ${ }^{1}$, L. Ferreyra ${ }^{4}$, C. Orozco ${ }^{5}$, E.E. Schneeberger ${ }^{5}$, H. Maldonado Ficco ${ }^{6}$, D. Baenas ${ }^{7}$, F. Colombres ${ }^{8}$, M. Mamani ${ }^{1}$, J.A. Maldonado Cocco ${ }^{9}$, E. Soriano ${ }^{4}$ ${ }^{1}$ Hospital B. Rivadavia, Buenos Aires, Argentina; ${ }^{2}$ Rheumazentrum Ruhrgebiet, Herne, Germany; ${ }^{3}$ Hospital la Paz, IdiPaz, Madrid, Spain; ${ }^{4}$ Hospital Italiano de Buenos Aires; ${ }^{5}$ Instituto de Rehabilitación Psicofísica (IREP), Buenos Aires; ${ }^{6}$ Hospital San Antonio de Padúa, Río Cuarto; ${ }^{7}$ Hospital Privado de Córdoba, Córdoba; ${ }^{8}$ Hospital de Clínicas Dr. Avellaneda, Tucumán; ${ }^{9}$ Consulting Profesor of Rheumatology, University of Buenos Aires, Buenos Aires, Argentina

Objectives: The aim of the study was to translate and validate the ASAS Health Index (ASAS-HI) for Argentinean patients with spondyloarthritis.

Methods: Translation was done using a forward-backward procedure and qualitative interview were done with the translation. Patients fulfilling ASAS classification criteria for either axial (axSpA) or periphereal SpA (pSpA) were included to test psychometric properties. Test-retest reliability was assessed by intraclass correlation coefficient (ICC) in patients without treatment changes (stable disease state). In patients who required therapeutic modifications due to changes of disease activity, responsiveness was evaluated using a standardized response mean (SRM). Construct validity against other health outcomes was evaluated by Spearman correlation. Internal consistency (Cronbach-alfa) and discriminative ability between ASAS-HI and ASDAS were assessed.

Results: Translation into Argentinean Spanish was accepted with minor changes. Fifty two patients were recruited [65\% male, mean (SD) age 39. 5 (12.5) years and median (IQR) disease duration $72(45-138)$ months]. Most of the patients had axSpA diagnosis (AS: 26, nr-axSpA: 18) while the rest had pSpA (8). The total score of the ASAS-HI was 7.4 (SD: 4.4), BASDAI: 4.4 (SD: 2.7), BASFI: 4.0 (SD: 3.1), ASDAS-CRP: 2.4 (SD: 0.9). Test-retest reliability (n: 20) was good ICC: 0.88 (95\%IC 0.76 to 0.98 ). Sensitivity to change was tested in 13 patients and SMR was -0.61 for those patients receiving TNF inhibitors ( $n: 11)$. Convergent validity ranged as hypothesized with Spearman correlations from low (age: 0.27 ) to good (pain: 0.65), (table 1). The ASAS-HI discriminated well between patients with different stages of disease activity and function irrespective of the measure applied (ASDAS, BASDAI and BASFI) (table 2). The internal consistency according to Cronbach's alfa was 0.81 .

Table 1. Spearmen correlation coefficient

\begin{tabular}{lcc}
\hline Characteristics & \multicolumn{2}{c}{ Spearmen correlation coefficient } \\
\cline { 2 - 3 } & ASAS-HI (0-17) & p value \\
\hline Age & 0.27 & $<0.05$ \\
Pain (0-10) & 0.65 & $<0.001$ \\
Night spinal pain (0-10) & 0.54 & $<0.001$ \\
ASDAS & 0.51 & $<0.001$ \\
BASDAI (0-10) & 0.60 & $<0.001$ \\
BASFI (0-10) & 0.54 & $<0.001$ \\
SF-36 Total & 0.46 & $<0.001$
\end{tabular}

Table 2. ASDAS Status Groups

\begin{tabular}{lcccc}
\hline & \multicolumn{4}{c}{ ASDAS Status Groups } \\
\cline { 2 - 5 } & Inactive $(\mathrm{n}: 9)$ & Moderate $(\mathrm{n}:$ 9) & High $(\mathrm{n}: 29)$ & very high $(\mathrm{n}: 5)$ \\
\hline ASAS-HI $(0-17)$ & $3.44( \pm 3.9)$ & $5.77( \pm 4.79)$ & $9.06( \pm 3.49)$ & $10.05( \pm 4.5)$ \\
BASFI $(0-10)$ & $0,53( \pm 0,35)$ & $1.41( \pm 1.40)$ & $5.5( \pm 2.46)$ & $6.46( \pm 3.12)$ \\
BASDAI $(0-10)$ & $1.21( \pm 0.49)$ & $2.37( \pm 1.7)$ & $5.73( \pm 1.91)$ & $6.46( \pm 3.38)$ \\
\hline
\end{tabular}

Conclusions: The Argentinean version of the ASAS-HI was comprehensive and reliable by patients with SpA. The ASAS-HI is a valid tool for assessing overall functioning and health in spondyloarthritis.

References:

[1] The ASAS Health Index (ASAS HI)a new tool to assess the health status of patients with spondyloarthritis, Clin Exp Rheumatol 2014;32:S105-S108.

Disclosure of Interest: V. Duarte Employee of: Novartis Argentina, U. Kiltz: None declared, V. Navarro-Compán: None declared, N. Lloves: None declared, G. Crespo Amaya: None declared, L. Ferreyra: None declared, C. Orozco: None declared, E. Schneeberger: None declared, H. Maldonado Ficco: None declared, D. Baenas: None declared, F. Colombres: None declared, M. Mamani: None declared, J. Maldonado Cocco: None declared, E. Soriano: None declared DOI: 10.1136/annrheumdis-2017-eular.4386

\section{SAT0428 WHICH CRITERIA FOR INFLAMMATORY BACK PAIN IN SPONDYLOARTHRITIS ARE OPTIMAL? DATA FROM THE SCREENING FOR AXIAL SPONDYLOARTHRITIS IN PSORIASIS, IRITIS, AND COLITIS STUDY (SASPIC)}

R. Carmona ${ }^{1}$, J. Yeung ${ }^{2}$, A. Masetto ${ }^{3}$, L. Martin ${ }^{4}$, S. Keeling ${ }^{5}$, J. Chan ${ }^{2}$, D. Mosher ${ }^{6}$, O. Ziouzina ${ }^{4}$, J. Paschke ${ }^{7}$, A. Carapellucci ${ }^{7}$, R.G. Lambert ${ }^{8}$, W.P. Maksymowych ${ }^{5,7} .{ }^{1}$ St. Joseph's Healthcare Hamilton, Hamilton; ${ }^{2}$ Medicine, University of British Columbia, Vancouver; ${ }^{3}$ Medicine, Université de Sherbrooke, Sherbrooke; ${ }^{4}$ Medicine, University of Calgary, Calgary; ${ }^{5}$ Medicine, University of Alberta, Edmonton; ${ }^{6}$ University of Calgary, Calgary; ${ }^{7}$ CaRE Arthritis; ${ }^{8}$ Radiology, University of Alberta, Edmonton, Canada

Background: Criteria for inflammatory back pain (IBP) in spondyloarthritis (SpA) include the Calin, Berlin, and Assessments in SpA International Society (ASAS) criteria, although no studies have undertaken comparative validation to determine which are optimal versus the rheumatologist expert opinion gold standard assessment.

Objectives: We aimed to compare IBP criteria in unselected patients presenting with undiagnosed back pain to rheumatology practice.

Methods: The Screening for Axial Spondyloarthritis in Psoriasis, Iritis, and Colitis (SASPIC) Study is aimed at the development and validation of a triage strategy for detection of axial SpA in patients presenting with undiagnosed back pain. Consecutive patients $\leq 45$ years of age with $\geq 3$ months undiagnosed back pain with any one of psoriasis, acute anterior uveitis, or colitis diagnosed by the relevant specialist undergo routine clinical evaluation by a rheumatologist for axial $\mathrm{SpA}$. The rheumatologist determines the presence or absence of IBP (defined as $<5$ or $>5$ on $0-10$ scale, respectively) and axial SpA (yes/no) after the clinical evaluation and review of labs (B27, CRP) and imaging ( $x$-ray, MRI). Clinical and laboratory data, radiographs and MRI scans are also assessed centrally for diagnosis of axial SpA (yes/no). We assessed sensitivity and specificity of each 